terie ergab, bis zu 2 Tagen im leicht bedeckten Glase an einem kühlen Orte stehen konnte, ehe die Algenbildung vor sich ging.

Ueber die Veränderlichkeit des Rothweinfarbstoffes. J. Erd$\operatorname{man} n^{*}$ ) hat eine Reihe von Versuchen über das Verhalten des Farbstoffes verschiedener Jahrgänge einer und derselben Sorte echten Bordeaux-Weines angestellt und ist zu dem beachtenswerthen Resultate gelangt, dass sich Natur und Reactionen des Rothweinfarbstoffes bei längerem Lagern nicht unerheblich verändern.

Salicylsäure im Wein weist $\mathrm{Yvon}^{* *}$ ) nach, indem er $20 \mathrm{cc}$ desselben mit $0,5 c c$ Salzsäure versetzt, darauf $3 c c$ Aether hinzugiesst und die mit dem Finger geschlossene Röhre mehrmals umdreht. Die ätherische Lösung wird direct auf eine Lösung yon Eisenchlorid gegossen. Eine violette Zone an der Berührungsstelle zeigt Salicylsäure an. Verdunstet man die abgehobene ätherische Lösung für sich, so kann die zurückbleibende Salicylsäure auch an ihren physikalischen Eigenschaften erkannt werden.

\title{
Ueber die Einwirkung des Chlors und Broms auf Fuchsin.
} Kürzlich hat F. Flückiger***) angegeben, dass verdünnte Fuchsinlösungen durch Zusatz von Chlorwasser auffallend verdunkelt und dann missfarbig würden, während etwas Bromdampf eine sehr reiche violette Färbung oder aach einiger Zeit die Abscheidung violetter Flocken bewirke; in beiden Fällen soll die dunklere Färbung sehr beständig sein. Da die Farbstóffe des Weins und der Himbeeren durch Brom und Chlor augenblicklich zerstört werden, so empfahl Flückiger Chlorwasser oder Brom zur Prüfung des Weines und Himbeersyrups auf Fuchsin.

E. Schaer $\uparrow$ ) hat über die Einwirkung des Chlors und Broms auf Fuchsin neuerdings Versuche angestellt und ist dabei zu folgenden Resultaten gelangt. Verdünnt man eine alkoholische Lösung von reinstem krystallisirtem Fuchsin mit Wasser bis zur hellrothen Färbung, so wird die Lösung durch einige Tropfen Chlor- oder Bromwasser oder durch minimale Mengen von Bromdampf entfärbt. Sind die Lösungen hingegen aus unreinem Fuchsin oder Fuchsin-Mutterlauge bereitet, so führen die-

*) Ber. d. deutsch. chem. Gesellsch. z. Berlin 11, 1870.

**) Pharm. Zeitsehr. f. Russland 16, 556.

***) Zeitschr. d. österr. Apothekervereins 15, 363 und diese Zeitschr. 17, 108.

$\dagger$ † Schweiz. Wochenschr. f. Pharm. 15, 99 und Arch. Pharm, 10, 376 (1878). 